\title{
Aula de campo: Subsídio de preservação e estudo da Pedra da Andorinha, Sobral/CE
}

\author{
Field Class:Preservation And Study of Pedra da Andorinha,Sobral - CE \\ SOUZA $^{1}$, D. B.; MARINHO, A. S. ${ }^{2}$; FARIAS ${ }^{3}$,C. S. S.; MEIRA ${ }^{4}$, S. A. \\ dimabrito1@gmail.com
}

\begin{abstract}
Resumo
O presente estudo apresenta uma discussão sobre a geomorfologia atual em áreas de intrusões graníticas e os processos envolvidos no seu desenvolvimento. O objeto de estudo é o inselberg denominado Pedra da Andorinha, inserida dentro da unidade de conservação municipal "Refugio de vida silvestre Pedra das Andorinhas", localizado em Taperuaba no município de Sobral-CE onde se destacam suas fisionomias e seus aspectos gerais, contextualizando a formação regional e suas características atuais. Os resultados foram obtidos a partirda atividade de campo, realizada nos dia 16 e 17 de junho,da disciplina de geomorfologia no curso de Geografia daUniversidade Federal do Ceará-UFC.
\end{abstract}

Palavras-chave: Inselberg. Formação geomorfológica.

\begin{abstract}
This study presents an analysis of the geomorphology existing in areas of granitic intrusions and processes involved in its development. The study object is the inselbergPedra da Andorinha, inserted into the municipal conservation unit "refuge wildlife of Pedra da Andorinha" located in Taperuaba in the city of Sobral - CE, which highlight their physiognomy and their general aspects, contextualizing regional training and its current characteristics. The results were obtained from field activity of geomorphology discipline in the course of Geography of the Universidade Federal do Ceará, held on June 16 and 17.
\end{abstract}

Keywords: Inselberg.Formation geomorphological. Fild class.

\section{INTRODUÇÃO}

A aula de campo pode ser descrita, sucintamente, enquanto uma viagem a um determinado lugar para pôr em prática os conceitos e discussões realizadas durante a componente teórica de uma determinada disciplina, sendo que essa atividade pode ser de caráter obrigatório ou optativo no currículo. Porém, é certo afirma que otrabalho de campodeve ser usado como subsidio de aprendizagem na graduação, sendo que a sua importância se amplia quando se trata de estudos da área da ciência geográfica, em espacial nas componentes curriculares do eixo da Geografia Física.

Suertegaray (2002, p. 67) salienta a importância da realização dos trabalhos de campo "como um instrumento da análise geográfica que permite o reconhecimento do objeto e que, fazendo parte de um método de investigação, permite a inserção do pesquisador no movimento da sociedadecomo um todo". O "campo" pode ser denominado enquantoum determinado local, área ou região, para onde o pesquisador vai, a fim de observar, registrar, descrever e explicar fatos ou fenômenos geográficos.(Cavalcanti 2007, p 02 apud, Pereira 2009, p. 106)

\footnotetext{
${ }^{1}$ Dimas de Brito Souza ,Departamento de Geografia/ Labocart, Universidade Federal do Ceará,Fortaleza-CE, Brasil 
Diante o exposto o presente artigo pretende abordar a importância da aula de campo em disciplinas da Geografia Física, bem como essas atividades podem contribuir para a instituição de ações conservacionistas por parte dos alunos e incentivar a tomada de atitudes responsáveis nas áreas visitadas. Para chegar a tal objetivo toma-se como estudo de caso o trabalho de campo realizado no âmbito da disciplina geomorfologia realizadas pelos alunos do curso de graduação em Geografia da Universidade Federal do Ceará, 16 e 17 de junho de 2016 para o Refúgio da Vida Silvestre Pedra da Andorinha, localizada no distrito de Taperuaba em Sobral/CE.

Como objetivo secundário pretende-se realizar uma análise dos aspectos geomorfológicos da Pedra da Andorinha, a qual está inserida Refugio da Vida Silvestre Pedra da Andorinha, sob as coordenadas 403'32.4'’S/3959'34’'W (Figura 01).

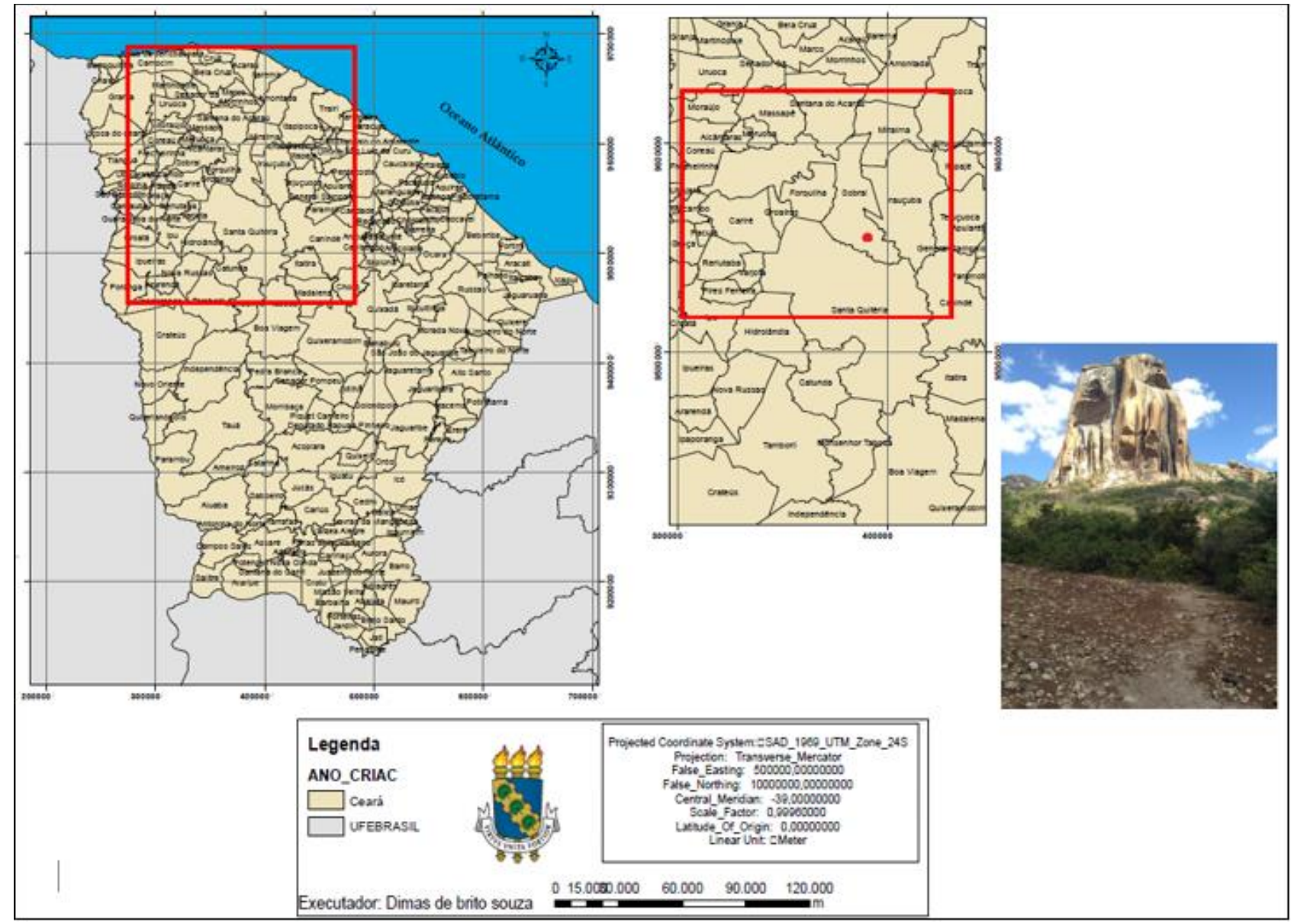

Figura 01: Mapa de localização. Fonte: SOUZA.D,B. (2016)

A Pedra da Andorinha, também conhecido como Serrote da Andorinha, é caracterizada por um inselberg, que foi definido por Kegel(1993apudGuerraeGuerra, 1993, p. 252), tendo como base estudos realizados no estado do Ceará e Piauí, por “elevações pouco alongadas, e relativamente ilhadas, cuja evolução se fez em função de um sistema de erosão, com clima semiárido". 


\section{METODOLOGIA}

A metodologia adotada para a realização desse artigo parte, primeiramente da busca de referencial teórico sobre os temas abordados e, num segundo momento, pela realização de um trabalho de campo para a área em análise.

A visita ao lugar foi feita durante a aula de campo da disciplina de Geomorfologia ofertada pelo Departamento de Geografia da Universidade Federal do Ceará nos dias 16 e 17 de junho de 2016. Foi utilizado de registros fotográficos, para a realização do campo se fez necessário a utilização de materiais didáticos, isso facilitou a relação ensino-aprendizagem em âmbitos geomorfológicos.

Durante o campo foi feita uma análise empírica do lugar. Foi observado o elementos que compõem o inselberge analisando o contexto geológico-geomorfológico regional e os processos de formação. Como abordado anteriormente a área de pesquisa é uma Unidade de Conservação Ambiental, e para realizar a visita foi necessário uma autorização previa. As Unidades de Conservação (UC) são ferramentas utilizadas para a conservação de ambientes singulares e/ou vulneráveis às ações antrópicas, essas áreas buscam a manutenção dos recursos naturais, o equilíbrio ambiental e assegurar as potencialidades locais.

Aulas de campo realizadas em Unidades de Conservação tem como potencialidade a capacidade de estimular e gerar em seus praticantes ações conservacionistas devido os objetivos intrínsecos a essas áreas e o estágio próximo ao "ambiente natural", sendo assim um contraponto aos ambientes urbanos que se apresentam extremamente artificializados.

\section{RESULTADOS E DISCUSSÃO}

\subsection{Aula de Campo na Ciência Geográfica}

Segundo Aparecida (2009, p.02), “quando se pensa num ensino de qualidade, sobretudo em Ciências, é indispensável um planejamento que articule trabalhos de campo com as atividades desenvolvidas em classe', Em meio a esse contexto Alentejano e Rocha-Leão (2006, p.53) abordam a importância dos trabalhos de campo na Geografia quando expõem que

Desde os primórdios da Geografia os trabalhos de campo são parte fundamental do método de trabalho dos geógrafos. Aliás, a sistematização da Geografia enquanto ciência muito deve ao conjunto de pesquisas e relatórios de campo elaborados anteriormente por viajantes, naturalistas e outros, verdadeiro manancial de informações que foram essenciais para a construção das bases para o desenvolvimento da Geografia.

O recanto da vida silvestre Pedra da Andorinha configurasse enquanto um lugar propício ao desenvolvimentos de pesquisas no âmbito da Geografia devido a diversidade de elementos 
geológico, geomorfológico e ecológicos presentes. A realização de aulas de campo em locais como esse, geram além de ser uma ferramenta de aprendizado e ensino, utilizando conhecimentos teóricos e impíricos para a formulação de resultados, gera subsídios para a toma de ações conservacionistas.

Como citado anteriormente a Pedra da Andorinha apresenta importância em muitos aspectos ambientais, sendo um deles a fauna, sendo predominante a presença de andorinhas. Ângelo (2005, p. 98) destaca que a principal ameaça para as aves brasileiras é a perda e a fragmentação de habitats. A Pedra da Andorinha é um habitat e precisa de ações conservacionistas para manter o máximo possível as suas características naturais, preservando assim a sua importância ambiental.

Com a realização do campo observou-se, junto com os alunos, um aumento pelo interesse em estudar e compreender os processos ambientais corridos na formação da Pedra da Andorinha, mas principalmente em manter sua área de preservação. Diante disso a aula de campo serviu como ferramenta de conscientização ambiental, "como eu vou preservar aquilo que não eu não conheço e não entendo?', esse foi um dos questionamentos levantados pelos alunos, sendo que a realização de aulas de campo suprem esse déficit, indo além da discussão teórica, propondo práticas e vivencias.

\subsection{Relato de Campo: Descrição Geomorfológica e Preservação da Pedra da Andorinha - CE}

O campo deinselbergues da Pedra da Andorinha se encontra em áreas de intrusões graníticas, sendo cientificamente conhecidas como batólitos, Essas intrusões originaram-se a em áreas que ocorreram a orogênese. No momento da colisão houve a formação de uma cadeia de montanhas, onde ocorreu uma grande pressão no limite crosta-manto, permitindo a ascensão do magma pela crosta entre as fraturas, que surgiram por causa das zonas de cisalhamento, deram origem aos batólitos e aosplútons graníticos. Esses corpos granitóides que hoje sustentam maciços e campos de inselbergs, nos últimos 540 milhões de anos eles estão apenas sendo exumados, e nessas exumações tem se originado essas feições de relevo(Informação verbal ${ }^{1}$ ).

Diante disso torna-se válida trazer uma definição do conceito de orogênese para o melhor entendimento do processo descrito anteriormente. Segundo Guerra e Guerra(1993, p. 338)

A orogênese é um conjunto de fenômenos que no ciclo geológico levam a formação de montanhas ou cadeias montanhosa, produzindo principalmente pelo dia morfismo (desdobramentos e falhas ou combinações destes). A orogênese reflete os diversos aspectos das forças endógenas, porem as formas de relevo dela resultante estão sempre esculpidas pelos agentes exógenos. A s áreas que foram visitadas durante o campo foram resultados desses processos.

\footnotetext{
${ }^{1}$ Informação fornecida por Rúbson Pinheiro Maia, durante a realização de aula de campo da disciplina de geomorfologia ofertada pelo departamento de geografia na UFC,emTaperuaba-Sobral/CE em junho de 2016
} 
Observa-se no mapa geológico(figura 02) áreas de intrusões graníticas ou copos granitóides, fruto da orogênese Brasiliana descrita anteriormente, que atualmente sustentam maciços e o campo de inselberg. Salienta-se que a Pedra das Andorinhas encontra-se nesse contexto geológico e que o mesmo mapa foi mostrado a turma enquanto auxilio didático-explicativo antes da ida ao trabalho de campo.

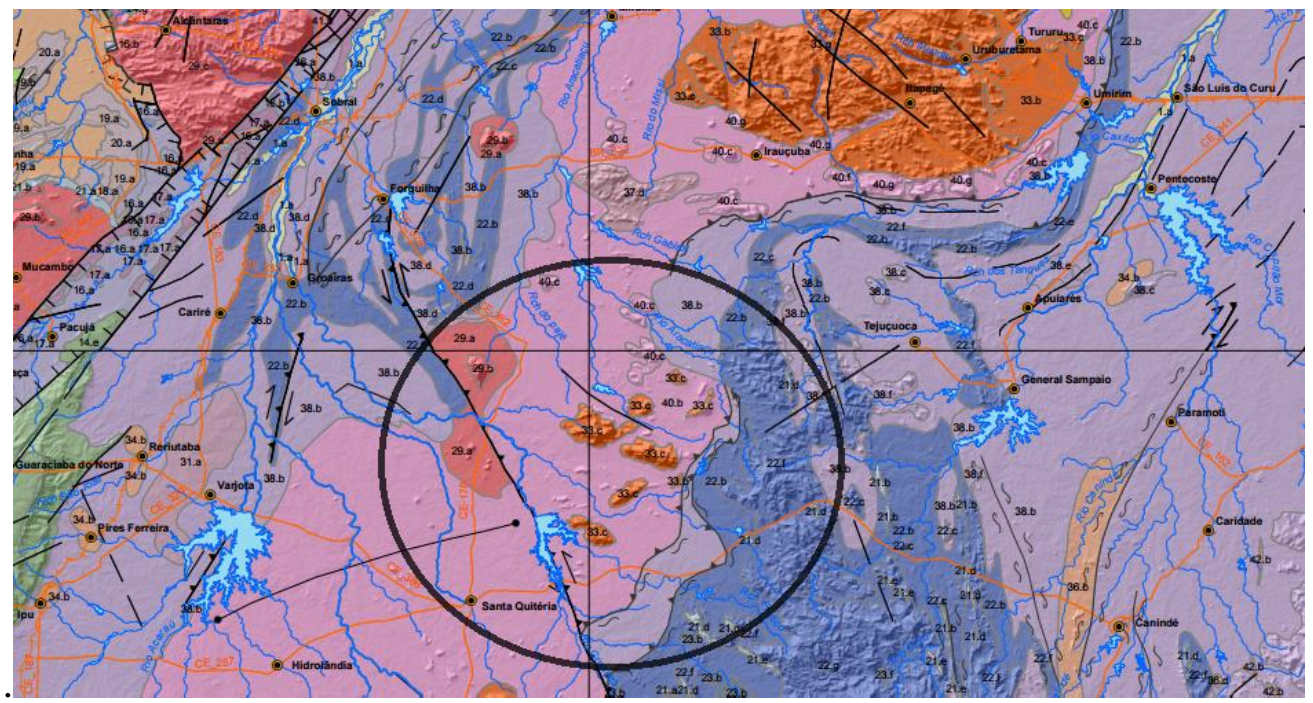

Figura02:Área do Campo de inselbergs em Taperuaba, Sobral - CE.Fonte:Recorte tirado do Mapa de Geodiversidade(2014).

Ainda expôs o papel das diferenças depressão e temperatura na formação dos batólitos granítico, os diques magmáticos são resfriados em sub superfície e ao longo do tempo são expostos e modelados a partir dos agentes intempéricos, resultando na formação do relevo de inselbergues. $\mathrm{Na}$ figura 03 observa-se esse processo por meio deuma simplificação didática. No primeiro momento temos a fratura sendo preenchida (Figura 3a), posteriormente o resfriamento e consolidação do magma em sub superfície (Figura 3b), seguido do início do processo de rebaixamento do relevo regional e afloramento do batólito (Figura 3c) e, por fim, a configuração atual do inselberg, bastante modificado pelo intemperismo oriundo dos agentes intempéricos, especialmente o clima(Figura 3c) (Informação verbal ${ }^{2}$ )

\footnotetext{
${ }^{2}$ Informação fornecida por Rúbson Pinheiro Maia, durante a realização de aula de campo da disciplina de geomorfologia ofertada pelo departamento de geografia na UFC,em Taperuaba-Sobral/CE em junho de 2016
} 

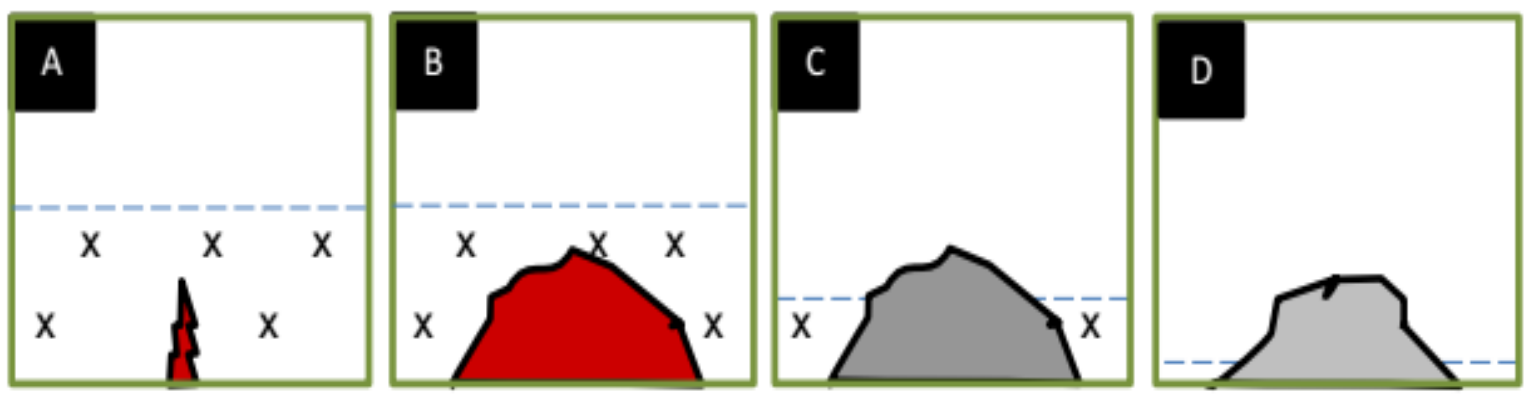

Figura 3: Formação dos inselbergues. Fonte: MARINHO, A. S.(2016).

A geologia regional da PedradaAndorinhaé composta tanto por campo de inselbergs como por maciços residuais, apesar das duas feições serem caracterizadas por um relevo de testemunho aos agentes intempéricos a diferença é que os maciços são conectados entre si, apresentam uma dimensão elevada e constam com camadas pedológicas que possibilita em muitos casos a fixação de vegetação, enquanto os inselbergues são menores, isolados na paisagem e apresentam forma esculpida por dissolução ou fraturamento.

Uma das feições visualizadas em campo foi o processo de escamação do corpo granitoide da Pedra da Andorinha (figuras 04 a e b). Tal processo é dado pelo fato de que quando acorre a exumação do corpo granitóideocorre uma mudança de pressão, a rocha que em sub superfície está sobre levada pressão passa para pressão atmosférica, diante disso o granito se expande e começa a soltar-se como escamas, que dependendoda composição da rocha pode variar sua espessura.

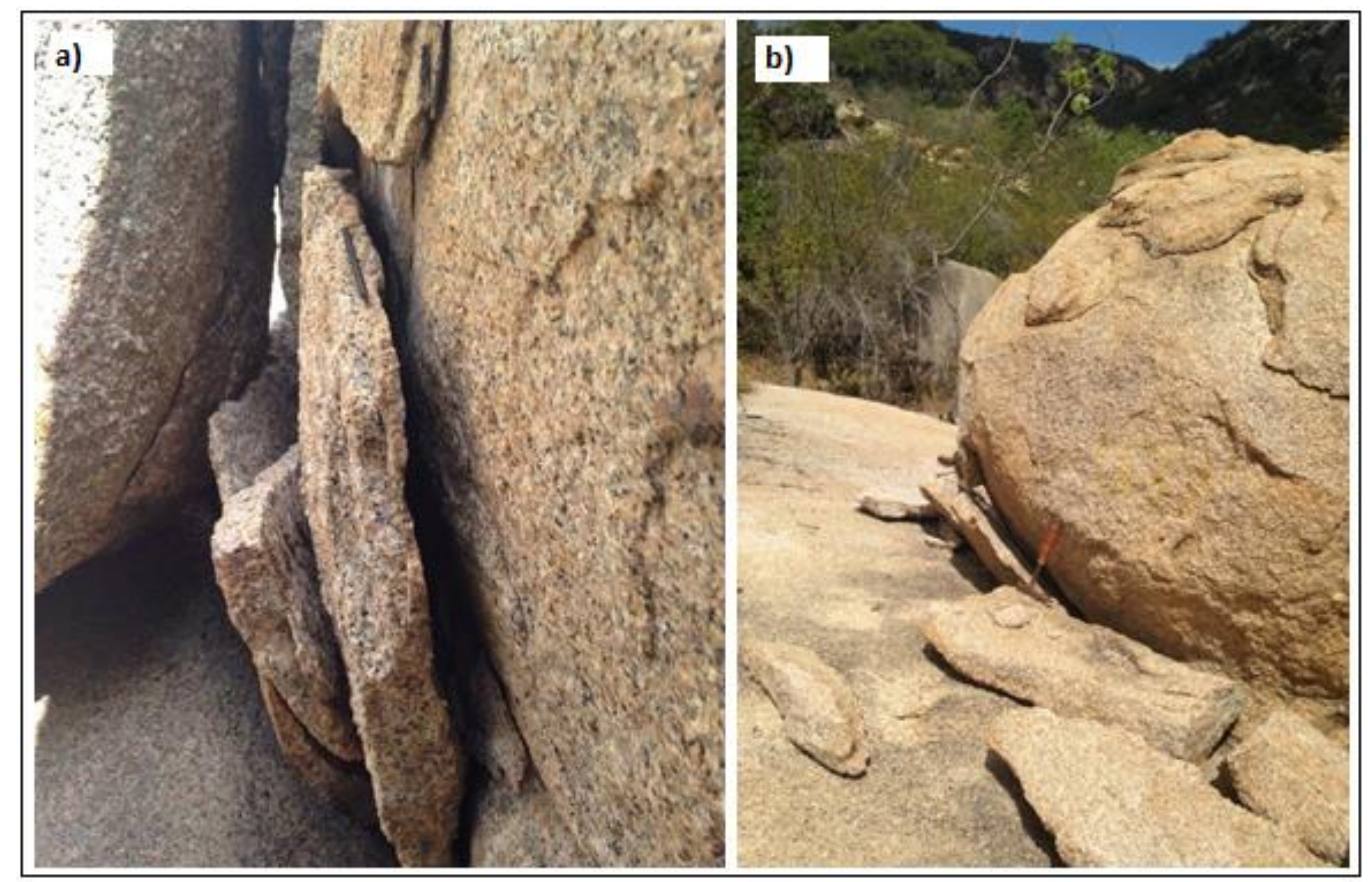

Figura 04: a) Escamação encontrada na base da Pedra das Andorinhas. b) Escamação encontrada na Pedra das Andorinhas. Fonte: FARIAS.C. S. S, 2016 
O aula de campo se estendeu para o município de Quixadá-Ceará, onde foram visitados mais dois tipos distintos de inselbergs, a Pedra do Cruzeiro e o Açude do Cedro, por meio da visita a esses locais foi possível realizar uma fazer uma comparação com o da Pedra da Andorinha, sendo de suma importância para distinguir os diferentes tipos de feições existentes.

A possibilidade de visitar diferentes locais que apresentam tipos distintos de inselbergues enriqueceu o conhecimento em torno da geomorfologia da região da depressão sertaneja do estado do Ceará. Durante as aulas ministradas em sala na disciplina de geomorfologia é discutido a gênese de um inselberg, bem como suas características principais, mas só durante o campo, nas visitas a essas diferentes áreas que se é compreendido a diversidade de feições que esse elemento geomorfológico pode apresentar dependendo do contexto geológico e climático local.

Asanálises realizadasdurante o campo revelam que a Pedra das Andorinhas se destaca por apresentar diferentes tipos de feições de dissolução, sendo que essas feições amplamente denominadas de "tafones" detêm uma elevada importância ecológica, já que são os locais onde andorinhas habitam.Relatos de uma moradora do local expõe que as andorinhas saem dos ninhos normalmente entre9:00 e 10:00 da manhã, a mesma ainda salienta que os pássaros fazem os ninhos nas cavidades do bloco granítico, demonstrando a relação existente entre esse aspecto da geodiversidade com a biodiversidade local, o que torna necessário alçar medidas de conservação do ambiente.

\section{CONSIDERAÇÕES FINAIS}

A Pedra das Andorinhas, apesar de sua relevância geomorfológica e ecológica, até o presente momento ainda apresenta poucos trabalhos realizados, sendo uma área carente de descrição geológica, geomorfológica, biogeográfica e ecológica aprofundadas. Tal fato é de suma importância já que a conservação do Reserva da Pedra das Andorinhas só será efetivamente realizado quando se tiver o conhecimento dos reais elementos que a compõe, pois somente assim será conhecido as potencialidades e vulnerabilidades da área, sendo essa a real base para o desenvolvimento de um planos de ações.

Diante disso o presente artigo se apresenta como uma discussão inicial sobre essa importante área localizada no município de Sobral, tendo como objetivo trazer visibilidade a mesma e incentivar a realização de novos estudos. Sendo que esses estudos devem dar importância aos conhecimentos dos moradores locais, pois, segundo as observações realizadas em campo, são esses que melhor compreendem a dinâmica e os processos presentes, diante disso a abordagem do 
etnoconhecimento torna-se necessáriopara o enriquecimento dos estudos e na consolidação de ações conservacionistas que visão a proteção desse ambiente.

Percebe-se ainda que a instituição daReservada Pedra da Andorinha se ergue enquanto um instrumento importante para a conservação da área, por meio do incentivo da mesma enquanto espaço de ensino-aprendizagem, ajudando alunos, pesquisadores e moradores a entender a importância ambiental do local.

Por fim, compreende-se que a aula de campo gera subsídios para o ensino-aprendizagem em disciplinas de geografia física, proporcionando o entendimento da formação do ambiente natural e possibilitando o questionamento dos aspectos geomorfológicos.

\section{REFERÊNCIAS}

ÂNGELO, M. M. GARCIA, F. I. Conservação de aves no Brasil. Megadiversidade. v. 01, n. 01, p. 98. Jul. 2005.

ALENTEANO, P. R. LEÃO, R. OTÁVIO, M. Trabalho de campo: Uma ferramenta essencial para os geógrafos ou um instrumento banalizado?.Boletim Paulista de Geografia. São Paulo, v. 01, n.84, p. 53 e 62.2006.

APARECIDA, A. V.; EUGÊNIO, R, S, D. Atividades de campo no ensino das ciências e na educação ambiental: refletindo sobre as potencialidades desta estratégia na prática escolar. Ensaio. São Paulo,v.02, n. 1, p. 02. 2009.

CEARÁ. Secretaria da Geologia, Mineração e Transformação Minera. Mapa da geodiversidade do Ceará. Fortaleza, 2006. Escala 1:750.000.

GUERRA, A. T.; GUERRA, A. J. T.Novo Dicionário Geológico-Geomorfológico. $6^{\text {a }}$ ed. Rio de Janeiro,1993.

SUERTEGARAY, D. M. A.. Pesquisa de campo emGeografia. GEOgraphia (UFF), v.4, n.7, p. 64-68, 2002.

\section{AGRADECIMENTOS}

Obrigado a todos que estiveram conosco durante o campo e na elaboração desse trabalho.

Recebido em: 14/08/2016

Aceito para publicação em: 01/10/2016 